\title{
SEGREGATION IN THE CLASSROOM
}

\section{AN EMPIRICAL TEST OF THE SCHELLING MODEL}

\author{
Gabriele Ruoff and Gerald Schneider
}

\begin{abstract}
Schelling's segregation model, one of the most influential contributions to the theory of collective choice, has almost exclusively been applied to the study of the housing market. We employ this analytical framework for a field experiment on the seating decisions within a classroom and thus a low-cost decision-making situation. In contrast to residential choices, individuals face minimal costs when choosing a seat and cannot within our subject pool reduce their neighbourhood choices to a visible criterion such as race. The experiment reveals nevertheless considerable segregation based on individual characteristics even in the absence of such a direct selection mechanism. Individual choices are largely determined by the 'costs' of a seat, the participants' psychological background and their self-declared seating behaviour. We also observe structure in the seating dynamic as individuals tend to sit in clusters, but avoid being directly placed next to another person. Our results strongly support the assertion that auditorium seating and equivalent social processes are not random but guided by both strategic reasoning and individual preferences.
\end{abstract}

KEY WORDS $\bullet$ duration models $\bullet$ group formation $\bullet$ heuristics $\bullet$ polarization $\bullet$ seating behaviour

\section{Introduction}

In his classic Micromotives and Macrobehavior Schelling (1978: 12) uses a low-cost decision making situation - the seating behaviour in an auditorium - as the initial example for his illustration of the difficulties in understanding aggregate social behaviour: '. . . there may be something about this process that reminds us of other situations in which people locate themselves voluntarily in some pattern

Konstanzer Online-Publikations-System (KOPS)

URL: http://www.ub.uni-konstanz.de/kops/volltexte/2007/2396/

URN: http://nbn-resolving.de/urn:nbn:de:bsz:352-opus-23969 
that does not possess evident advantages even for the people who by their own choices form the pattern.' Yet, Schelling left this particular application unexplored. To develop his famous segregation model, he switched to a high-cost decision-making situation and analysed the patterns that emerge from individual residential decisions. $\mathrm{He}$ conceived of these choices, in his own words, as a collective 'tipping' process in which the entrance of minority members alters the 'mixup' between the different races. In the end, segregation occurs because individuals do not like to belong to the minority despite a possible tolerance towards racial diversity. ${ }^{1}$

The segregation model has influenced many disciplines, ranging from economic geography (Krugman 1994, Batten 2001) over demography (Clark 1991, 1992), computer science, physics and mathematics (Pollicott and Weiss 2001) to sociology (Bruch and Mare 2003). Many computational studies have qualified Schelling's bold conjecture. They demonstrate, for instance, that segregation hinges on the specification of the utility function (Bruch and Mare 2003) or show that segregation also occurs under less restrictive assumptions than the ones originally used (Pancs and Vriend 2003).

Interestingly, most applications of the segregation model relate to residential choices or similar contexts in which a visible sign of differentiation between individuals often exists and where decisions are costly. There is, to our knowledge, no study that tests empirically the dynamics of locational decision making in a low-cost surrounding such as the one originally devised by Schelling (1978) in his monograph. We will use a classroom experiment to assess whether we can observe segregational patterns in the collective process of auditorium seating even in the absence of a clear-cut standard of differentiation. Our article examines whether subjects are guided in their seating behaviour by the presence of already existing groups or rather minimize the walking distance to their seat. We also explore whether the socio-psychological background of the students, the availability of seats close by or rather their declared seating behaviour accounts for the time until they enter the classroom. The inclusion of psychological variables is in line with Schelling's implicit hypotheses and can also be justified through the increasing reliance on such concepts in behavioural economics (e.g. Tirole 2002) and political science (e.g. Schneider and Krämer 2004).

The results support, by and large, Schelling's conjecture that informal rules guide aggregate social behaviour. Although the 'cost' of a seat, measured through various distance indicators, is an 
important explanatory concept, simple cost-benefit calculations are not the only driving force in auditorium seating. The field experiment rather reveals that arbitrary locational choices by those who enter a room early influence the decisions by students who enter some time later. Actors have also a tendency to sit in clusters, but prefer to sit without a direct neighbour despite their wish to be close to a group. The self-declared seating habits and some sociopsychological factors are other key explanatory factors.

This article is structured as follows: in section 2 we present the Schelling model in more detail, discuss the qualifications that have been made throughout the past 35 years and derive some hypotheses from the theoretical and empirical literature. Section 3 operationalizes key concepts and describes the setup of the experiment. Section 4 presents the results, and we conclude with a brief summary and discussion of the major implications of our field experiment.

\section{Theory}

Schelling's segregation model is one of the most influential contributions to the question of how self-interested agents unintentionally create discernible patterns of social interaction. One of the archetypical examples is the seating behaviour in an auditorium or a classroom. Schelling (1978) introduced a personal experience to describe the frequent pattern of the audience not wishing to sit in the front rows.

His segregation model attempts to explain similar collective processes. Unfortunately, Schelling's main application refers to a situation in which individual choices, unlike seating in an auditorium, are very costly. He studied in detail how segregated neighbourhoods can emerge despite racial tolerance. Key to his model is the assumption that individuals care about the race of the people among whom they live and that they are able to observe the racial setup in their surrounding. If these conditions are met, people start to move to a more segregated area once the racial setup in their neighbourhoods surpasses their individual acceptance level.

Although the differences in the preferences of the individuals are minor, polarized patterns in collective behaviour such as segregation can be observed. Schelling's model thus stands like the Prisoners' Dilemma or the Centipede Game for one of those archetypical situations in which the collective outcome is incentive-compatible, but in 
opposition to what would be socially desirable. The process through which this unfortunate equilibrium is achieved is far from being random. As Schelling's early agent-based simulation has shown, individual optimization can lead to the polarization of neighbourhoods.

Some studies have explored how marked the effect of racial preferences is on neighbourhood choices. Farley et al. (1994) see segregation mainly as a consequence of white stereotyping of integrated neighbourhoods. Bobo and Zubrinsky (1996) stress the importance of perceived discrimination rather than ethnocentrism, and Emerson et al. (2001) show, based on survey results, that a predominantly black neighbourhood diminishes the likelihood of a white respondent buying a home, while no such effect can be observed for neighbourhoods dominated by Asians or Hispanics. Although he does not downplay the role of discrimination or income, Clark (2003: 247-8; see also Clark 1991, 1992) supports Schelling's assumption that own-race preferences are key in understanding segregation patterns: 'all groups are open to integration at some level, but the alternate, and understandable, choice is . . . to prefer neighborhoods which are a plurality of own race neighbors. The results are consistent with theoretical arguments of Schelling (1971).'

The seating behaviour of the ethnically quite homogenous students that we are studying here differs from residential choices in an ethnically mixed neighbourhood in at least two dimensions. First, students are prevented from making their decisions on a visible criterion such as race. The impossibility of figuring out the profile of a potential neighbour leads us to the question of whether or not we can observe segregation despite the lack of such an obvious heuristic. Segregation could result if students with a particular background have a higher likelihood of joining a group of similar students. The second distinction of seating behaviour from residential choices has to do with the importance of the situation. Although finding a good seat might matter for students suffering from sight problems, choosing a bad seat is only detrimental during the time that one spends in a particular class. In marked contrast to residential choices, seating decisions are thus largely inconsequential and relatively costless.

A mix of psychological factors, cost-benefit calculations and peer pressure affects the individual decision on where the audience in an auditorium would like to sit. The most obvious conjecture is that 
individual decisions are influenced by the easiness of obtaining an attractive seat. This means, in the words of Schelling (1978: 14), that 'everybody likes to sit as close to the rear as possible'. We thus expect for our classroom experiment that the more costly it is to reach a seat, the less likely it is that someone will occupy it. Seats that are close to the entrance are the primary targets of early arriving students. A second consideration is that people avoid standing up. This means that seats in the middle of a row are more likely to be taken than distant end seats. A third, and potentially more important consideration, as Schelling (1978) colourfully observed, is that an audience avoids sitting too close to the lecturer. This has the typical effect that front seats tend to be empty, whereas the benches in the back are crammed. This pattern suggests that people avoid the cost of social exposure as long as standing out and isolation do not carry a specific benefit. We suspect that the advantages of anonymity often grow with the size of an auditorium. Obviously some individuals might weigh these three cost factors differently. We believe, however, that proximity to the entrance, the avoidance of standing and the search for anonymity are key considerations at the average.

Hypothesis 1 The more costly it is to reach a seat, the longer it takes for it to be occupied.

The transaction costs related to sitting down on an attractive seat are, however, not purely influenced by the architecture of an auditorium. Since seating is an interactive process, individual behaviour is influenced by the choices others have already made. We expect that people use the location of the first occupied seats as a heuristic and choose to sit close to these initial clusters. Similarly, they might also tend to sit as close as possible to each other. Because we conducted the experiment at the beginning of the winter term in a mandatory class, we cannot expect that students necessarily arrive in groups or place themselves next to someone they know from a previous semester. Schelling (1978: 15) speculated about a similar mechanism and wrote: 'everybody wants to sit to the rear of everybody else'. We believe that students want to avoid the social costs of being perceived as outcasts. This conjecture is in agreement with Schelling (1978: 15) who originally wrote that 'everybody wants to sit where he is close to people, either to be sociable or to avoid being conspicuously alone'. 
Hypothesis 2 Subjects prefer to sit next to another person, and close to an initial cluster of people.

The preferences of individuals will, as indicated, differ from one another. While some people might prefer to sit close to another person, others want to concentrate on the upcoming lecture and sit alone. They might also disregard the costs of a longer walk to a seat or of forcing other people to stand up. We can distinguish between two sorts of personal features. One of them is the selfdeclared preference of an individual for sitting alone or for disregarding the social costs of his or her seating behaviour. How the preference for a particular seat has evolved is of no concern here. We can speculate with Schelling (1978: 16) that the lack of enthusiasm for front-row seats is a consequence of personal experience: 'Still another hypothesis is that most members of the audience developed their seating habits in other times and places, where they found disadvantages in sitting down front'. Preferences might also have a psychological foundation. In a similar experiment to the one reported here, Mann and Taylor (1969) discovered that people who join a queue are overly optimistic. We particularly expect that self-assured and dominant people behave in the same fashion in the classroom. If this expectation were to prove right, we would find segregation to be a pattern of social behaviour even in a trivial human context.

Hypothesis 3 The social psychological background and the selfdeclared seating preferences influence the time of entry and the likelihood of sitting next to another person.

We have used a host of psychological factors to assess whether the personal background of an individual influences his or her seating behaviour: self-assurance (or lack of), sociability, dominance, extroversion and masculinity. Although one might have the impression that these variables are closely related, rank order correlation coefficients do not exceed 0.4 .

\section{Research Design}

\subsection{Design of the Experiment}

The experiment was conducted during the first two weeks of the winter term 2003/4 at the University of Konstanz. We selected two 
different compulsory lectures - 'Research Design' and 'Personnel and Organisation' - offered by the Department of Politics and Management for the test of our hypotheses. We conducted our field experiment at the beginning of the term to avoid claims for a specific seat or other traditions influencing seating behaviour.

The experiment was divided into two phases. First, we filmed how the lecture hall was filled. At the same time we handed out a small questionnaire to gather personal information from the students such as age, sex or the number of semesters they have spent at the university. We also asked them whether they were content with their chosen seat or whether they preferred another one. To assess who chose a particular seat we handed out serial numbers to the students before they were entering the room. This procedure enabled us to note for every participating student their entrance time and the chosen seat.

Part two of the experiment took place during the tutorials of the two lectures and consisted of the completion of a more detailed questionnaire. This questionnaire contains seven personal questions and 24 questions about seating preferences and about spontaneous behaviour. ${ }^{2}$ Out of these 24 questions we built three additive indices on spontaneity, the social aspect of seat choice and the locational aspect of seat choice. We have also included a standardized personality inventory, the Freiburger Persönlichkeitsinventar (FPI), ${ }^{3}$ in this questionnaire. This inventory consists of 212 questions that should enable a researcher to assess the personality of a respondent over 12 dimensions. These concepts are: nervousness; spontaneous aggressiveness; self-assurance; excitability; sociability; composure; pursuit of dominance; inhibitedness; openness; extroversion; emotional instability; and masculinity. As indicated beforehand, we only examined the effect of five of these concepts on individual seating behaviour. We asked the students to respond to all these questions in the tutorials, which should have offered them the chance to answer sincerely and without time constraints.

The first author, who acted as an instructor in all tutorials, explained simultaneously how the questionnaire should be filled out and assured the participants that the data would be treated confidentially. One disadvantage of splitting up the experiment into two phases is that not all students who took part in the lecture were present at one of the tutorials. Of the students who participated in the lecture 32 did not go to a tutorial; conversely, 23 students did not attend the lecture, but came to one of the tutorials. 


\subsection{Dataset}

Because construction of the dataset for one class took considerable time, we restricted our examination to the behaviour of the students during the research design class, a mandatory course for graduate students. In addition to the variables explained below, the dataset contains the location of the chosen seat (row and seat number), whether the seat is located at the end of a row, whether the student was the first to sit in this row, whether the student came in alone or together with other students, whether he or she was late and some further aspects. The dataset additionally reports the students' sex, age, number of semesters in attendance at the university, whether she/he is a foreign student, smoker, etc. All 53 seats that were not occupied during the lecture were incorporated as single observations.

\subsection{Dependent Variable}

The dependent variable of the first model, the cost model, labelled seating time, refers to the point in time when a student occupies a seat. Time is measured in minutes. We starting counting 45 minutes before the lecturer entered the room. The first seat is occupied at minute 13 and the last seat at minute 72.5 . For all seats remaining unoccupied time is set to 90 minutes. The first dependent variable entering time of the psychological models is the point in time when a student enters the room; the coding is analogous to seating time. The second dependent variable of the psychological models is the dummy variable neighbour; it measures whether any seat next to this seat or any of the three seats in front or behind this seat was occupied when the student sat down. This variable is at the same time one of the independent variables in the cost model. Finally, the last dependent variable of the psychological models - dubbed cluster - is a dummy measuring whether the occupied seat is located within one of the initial clusters as explained in the next paragraph.

\subsection{Independent Variables}

\subsubsection{Seat Attributes}

The first independent variable, labelled rowcosts, measures in metres the actual distance from the entrance to the particular row in which the seat is located. The second variable - crosscosts - comprises the 
actual distance covered within each row measured in number of seats. Neighbour is a dummy variable representing whether any seat next to this seat or any of the three seats in front of or behind this seat was occupied when a student sat down. Cluster 1, cluster2 and cluster 3 are categorical variables telling us whether or not the occupied seat is located within one of the initial clusters. These three clusters are defined by the first 10 students choosing a seat. As they sat together in three small groups which were located at different places of the auditorium we declared these locations to be the centres of the initial clusters. Then we assigned, in correspondence to their proximity to the centre, different values to the surrounding seats. Value 1 stands for very close seats and is assigned to the direct neighbours to these central seats and to the seats directly behind or in front of them. For all seats which are located in the second row behind or in front of the central seats or which are located three seats adjacent to the central seats within this particular row, we assigned a value of 0.5 . The number of 0.25 was allotted to seats that were located directly behind or next to a seat valued 0.5 . To all other seats we assigned a value of 0 , indicating they were not part of this initial cluster. Every seat, occupied or not, received a value for each cluster 1 to 3 indicating whether the seat was part of this cluster. ${ }^{4}$ Finally, we included the control variable Changed seat, which takes the value 1 if the seat was left for another seat and 0 if the seat remained occupied by this student.

\subsubsection{Declared Seating Preferences}

From the 24 questions we posed on seating preferences and spontaneous behaviour we have built three additive indices. ${ }^{5}$ Index 1 on spontaneity versus self-restraint ranges from 0 standing for very tense to 5 referring to a very spontaneous person. Index 2 on the social aspect of seat choice considers the question of whether a student wants to sit close to another whom he or she already knows: 0 stands for 'it is not important who is sitting next to me' and 6 stands for 'it is very important who is sitting next to me'. Index 3 on the locational aspect of seat choice measures the extent to which a student takes factors such as the proximity to the entrance or to a window or the distance to the lecturer into account while choosing her/his seat: 0 refers to students for whom these factors play no role and 5 corresponds to students who place a high importance on these factors. ${ }^{6}$ 


\subsubsection{Psychological Variables}

From the 12 different concepts available from the FPI we selected five for inclusion in our final analysis. These variables were selfassurance, sociability, pursuit of dominance, extroversion and masculinity. We chose these concepts because we think they best reflect the decisive factors in seating behaviour. All concepts are measured on a scale ranging from 1 to $9 .^{7}$

From the concepts nervousness, self-assurance, composure and emotional instability, which all are trying to identify the mental state of an individual, we chose the second because we considered self-assurance to be the decisive aspect in choosing a particular seat. A low score on the self-assurance scale reflects people who are easily distempered, often lonesome, and suffer from a lack of concentration and from a sense of inferiority. The concepts spontaneous aggressiveness, excitability and pursuit of dominance all refer to different aspects of aggressiveness; we chose the last because selecting a certain seat should not be influenced by the fact that a person tends to be spontanously aggressive or quick-tempered but rather because she is more or less dominant. Reactive aggressive people, those who try to assert themselves and who have an egocentric world view, score high on the pursuit of dominance scale. Sociability and inhibitedness both deal with the way in which a subject acts in the presence of other people. In our experiment the question of whether or not a subject likes to be with other people was thought to be central to this research. Therefore, inhibitedness, which measures whether a subject is unconstrained and self-confident, was less well-suited in this context; thus sociability was selected. A high score on this scale represents a person who makes friends easily, is searching for contact and is very active and communicative.

We preferred extroversion over openness because the main focus of the former concept lies in the ability to make contact and to talk with other people. Openness, conversely, is dealing with selfcriticalness and thus the question of whether or not someone is able to admit failures. A high score on the extroversion scale represents a person who is looking for contact and is very communicative and impulsive. In addition, we included in our analysis the concept masculinity. The other concepts do not cover this personality feature, which applies to both sexes. A low score corresponds to people with a typical female self-portrayal.

Table 1 summarizes the concepts that we will use in the subsequent statistical analysis. As we investigate the influence of the inde- 
pendent variables on the seating and the entering time, we use Cox regressions as a first estimation technique. A second part of the statistical examination refers to the question of whether or not someone sits in a cluster. We use logistic regression models to analyse whether or not people prefer to be part of a group.

\section{Results}

The experiment involved altogether 135 students (64 female; 71 male). The average time they had spent at the university was 5.97 semesters. The age span ranged from 20-30-years old, with the exception of one person who was 55, most students were 2124 -years old. The majority of the students, $94 \%$, were satisfied with the location of their seat. The seating pattern evolved largely as expected: no student chose a seat in the first row and, only one tudent sat in the second row. Most students sat in rows 6 or 9 . One student sat on the floor although there were still seats available. The final seating pattern is illustrated in Figure 1. Seats represented as crosses were not available in the classroom that we chose for our experiment. We distinguish between different periods marked by different shades of grey to illustrate the emergence of the seating patterns.

As Figure 1 clearly shows, seating follows certain unwritten rules. While early individuals would rather sit close to the entrance in the beginning, they also avoid sitting too far away from other people. This shows that early seating serves as a signpost to other participants. The nascent clusters contain thus, in other words, important information for people who arrive later. This is a first indication that seating behaviour in a classroom, and most likely in other contexts as well, is far from being random but follows certain informal rules. The analysis also confirms Schelling's observation that the audience tries to avoid sitting too close to the lecturer.

We will try to substantiate this inductive finding in the following. Table 2 summarizes three duration models. Model 1 examines the effect of the 'costs' of a seat on the time until a seat is taken, while model 2 examines the role of social costs and, model 3 allows us to examine the relative importance of the different predictors.

The duration regressions reported in Table 2 show clearly that seating behaviour in an auditorium is not only influenced by the individual costs of finding a seat. The decisions by the early entrants 


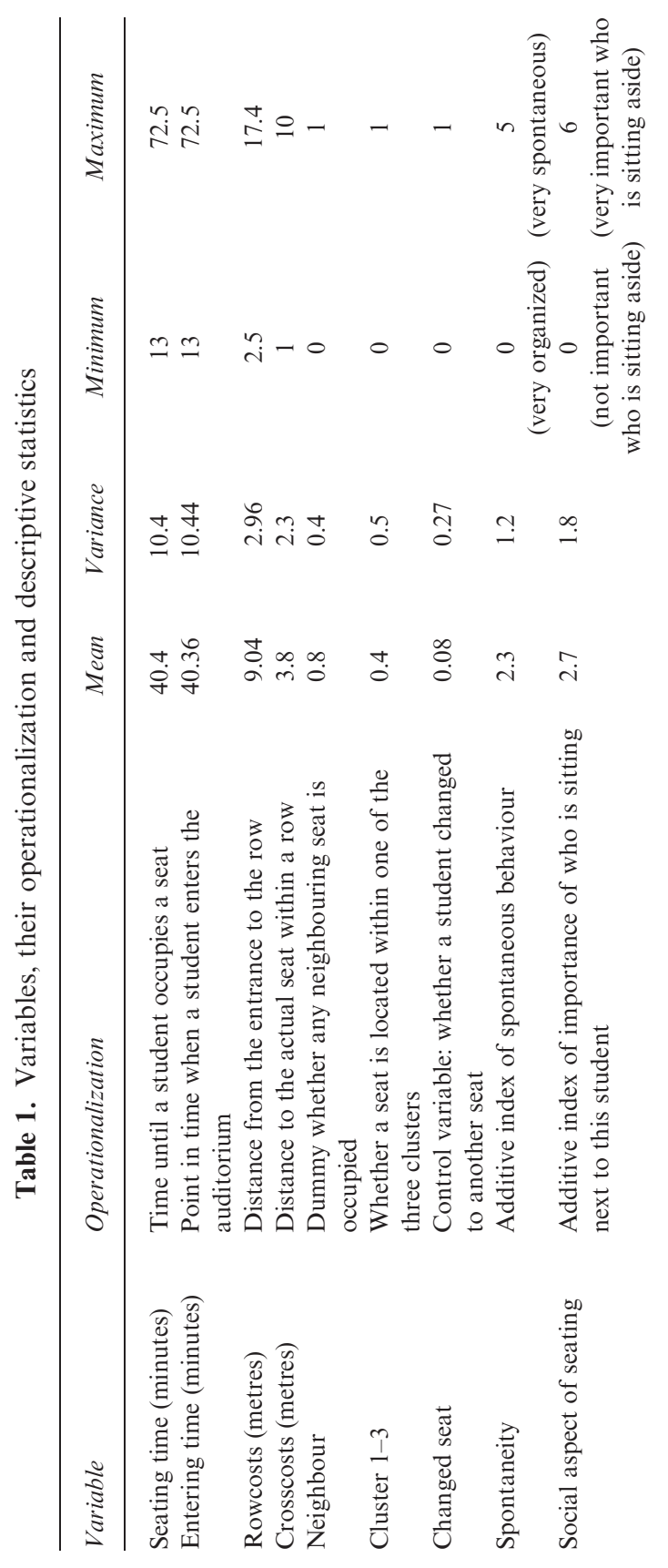




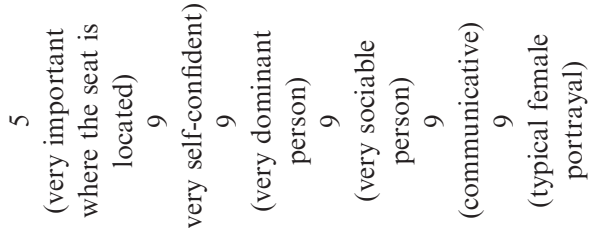

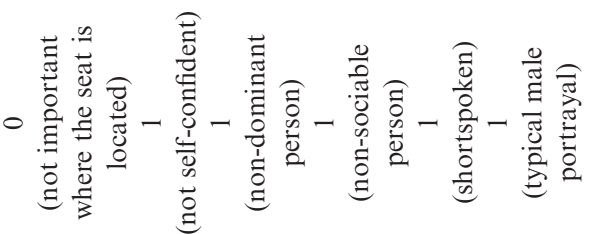

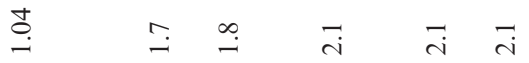

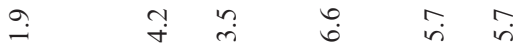

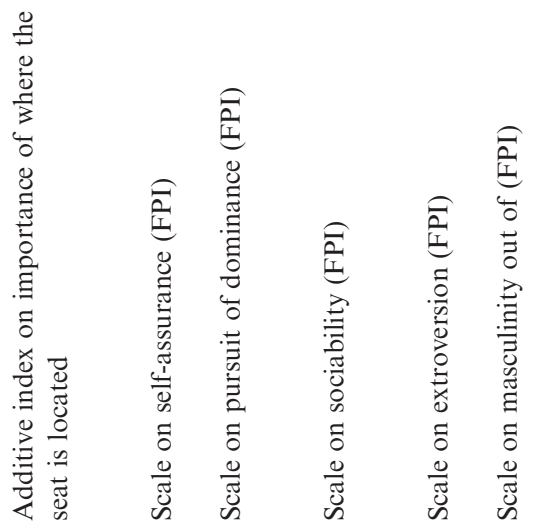

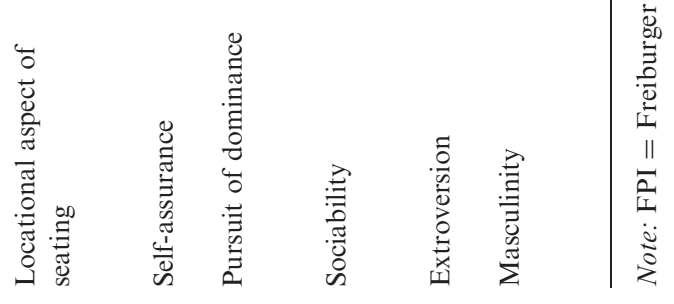


(A) Until minute 23.3

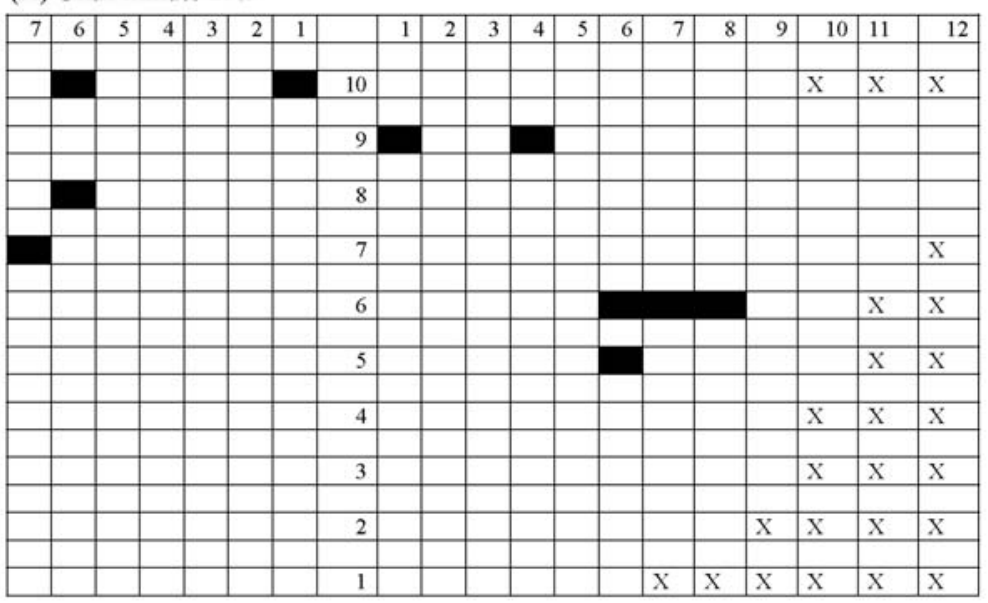

(B) Until minute 31.5

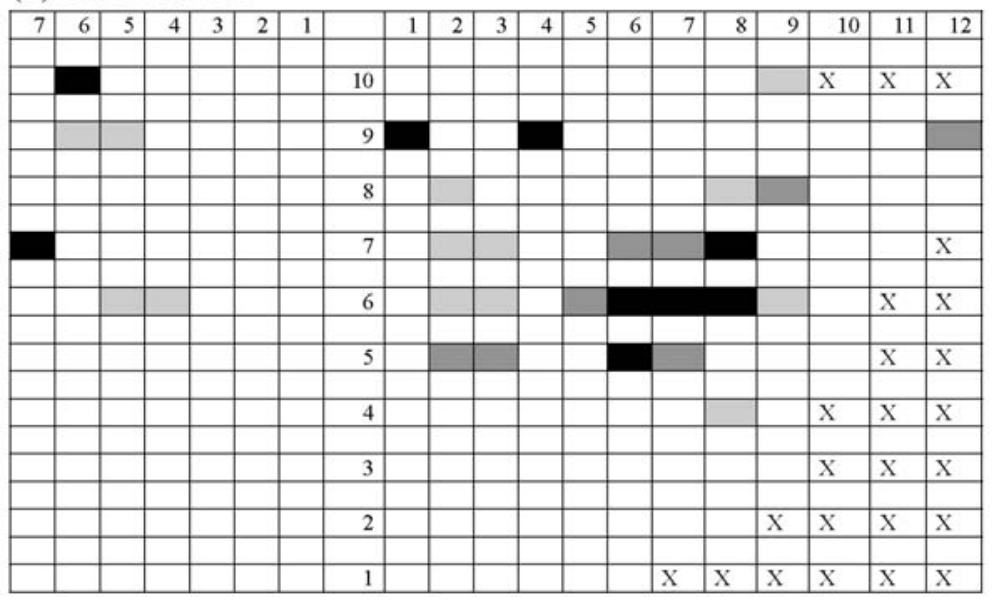


(C) Until minute 43

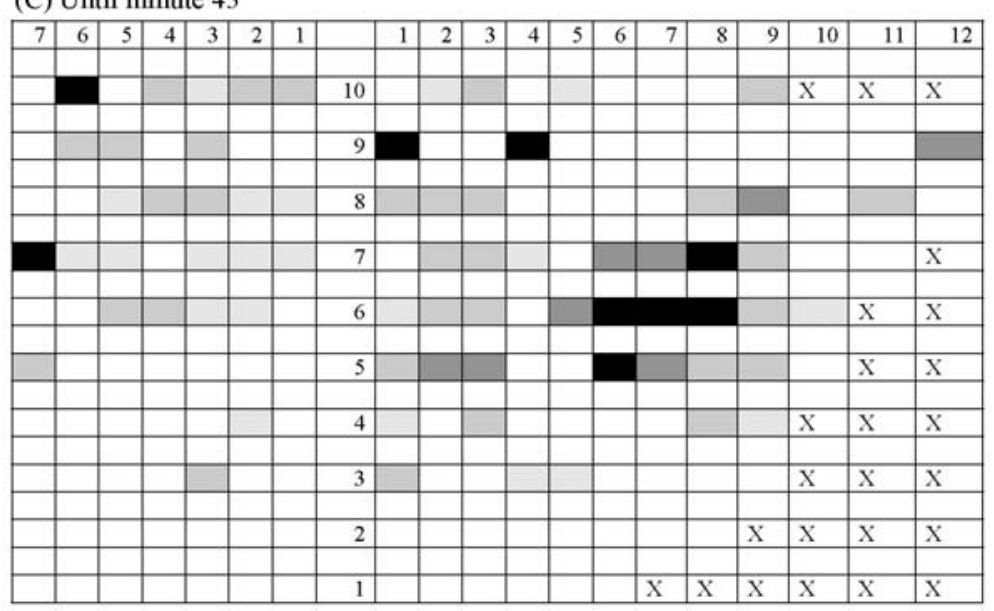

(D) End Pattern

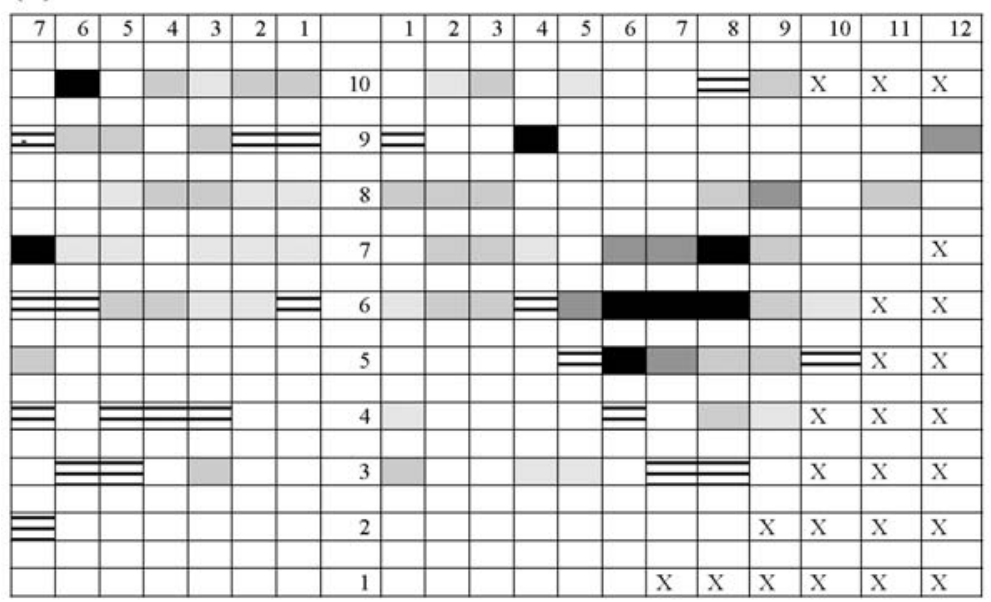

Figure 1. Seating pattern

Notes:

Darker colour shade indicates earlier entry time.

Fields marked with an $\mathrm{X}$ were not available as seats. 
Table 2. Effects on the duration until a seat is taken (Cox proportional hazard models)

\begin{tabular}{lccc}
\hline Variable & $\begin{array}{c}\text { Model 1 } \\
\text { Seating time }\end{array}$ & $\begin{array}{c}\text { Model 2 } \\
\text { Seating time }\end{array}$ & $\begin{array}{c}\text { Model 3 } \\
\text { Seating time }\end{array}$ \\
\hline Rowcosts & 0.916 & & 0.915 \\
Crosscosts & $(0.022)^{* * *}$ & & $(0.025)^{* * *}$ \\
Changed seat & 0.945 & & 0.921 \\
& $(0.034)$ & & $(0.036)^{* *}$ \\
Neighbour & 3.45 & 4.722 & 3.618 \\
Cluster1 & $(1.006)^{* * *}$ & $(1.441)^{* * *}$ & $(1.128)^{* * *}$ \\
Cluster2 & & 0.626 & 0.563 \\
Cluster3 & & $(0.119)^{* *}$ & $(0.116)^{* * *}$ \\
& & 5.063 & 5.27 \\
Observations & & $(1.750)^{* * *}$ & $(1.998)^{* * *}$ \\
Log likelihood & & 1.860 & 1.671 \\
& & $(0.539)^{* * *}$ & $(0.493)^{*}$ \\
\hline
\end{tabular}

Notes:

Hazard ratios reported; standard errors in parentheses.

* significant at $10 \%$; ** significant at $5 \%$; *** significant at $1 \%$.

are more decisive and serve as an important heuristic for latecomers. The clusters that have been formed in the first phase attract students to varying degrees. While the relatively centrally located clusterl seems to be especially attractive, the more peripheral cluster 2 does not attract students to the same extent. The overall impression that one can gain is nevertheless that most individuals take the social costs of their seating into account and prefer to be relatively close to already seated students. While people thus tend to form groups, they are nevertheless not necessarily striving for a seat next to another person. As the parameter of neighbour evinces, which is less than 1 , they tend to sit in a cluster without a direct neighbour. This pattern also remains robust when we integrate the cost and the cluster model in the last equation.

The analysis conducted so far demonstrates that social interaction structures the filling of an auditorium. Our regression models have nevertheless not indicated whether or not we can expect some psychological characteristics influence the seating behaviour in addition 
to the individual and social costs of a seat. Table 3 presents various Cox proportional hazard models to evaluate the relative importance of the personal attributes of a student on the time that he or she enters the classroom. Model 1 integrates the insights from above and shows how the costs of a seat and the presence of a cluster influence the time until the seat is taken. Model 2 examines the influence of the self-declared seating habits and social behaviour on the duration until a seat is taken, and model 3 does the same for the psychological attributes of a subject. Model 4 summarizes the effect of those factors that exert a systematic influence in models $1-3$.

Table 3 demonstrates for the second model, which comprises the effect of the declared seating preferences, that students who see themselves as being spontaneous tend to arrive later; whereas students who place more importance on the location of their seat arrive earlier. Both variables seem to lose their influence when incorporated into the fourth model. The variable social aspect of a seat, which measures whether the neighbouring seats are occupied and similar aspects, does not exert any noteworthy influence. According to Table 3, students who care about who is sitting next to them enter the auditorium earlier.

The third model is built on our expectation that students who are self-confident and extroverted arrive later. Sociable people conversely enter earlier. All three variables, self-assurance, sociability and extroversion, still exert their significant influence in the integrated model. The variables pursuit of dominance and masculinity do not seem to play a clear role concerning the entering time decision.

The integrated model shows that when all three kinds of different variables are taken together only some of the cost factors continue to exert a strong influence. These are rowcost, neighbour and clusterl. Cluster 2 and cluster 3 and crosscosts lose their influence conversely. Declared seating preferences no longer seem to play a crucial role whereas some psychological factors (extroversion, sociability and self-assurance) still exert noteworthy/significant influence.

To figure out the possible segregation patterns in a student classroom, we examined the effect of the self-declared background of an individual and his or her psychological profile on the decision of whether or not to sit next to another person and/or whether he or she chooses a seat located in one of the original clusters. We report these results in Table 4. Models 1 and 2 examine whether someone sits next to another person; models 3 to 5 analyse which 
Table 3. Effects on the time until a student enters the auditorium (Cox proportional hazard models)

\begin{tabular}{|c|c|c|c|c|}
\hline Variable & $\begin{array}{c}\text { Model } 1 \\
\text { Entering time }\end{array}$ & $\begin{array}{c}\text { Model } 2 \\
\text { Entering time }\end{array}$ & $\begin{array}{c}\text { Model } 3 \\
\text { Entering time }\end{array}$ & $\begin{array}{c}\text { Model } 4 \\
\text { Entering time }\end{array}$ \\
\hline Rowcosts & $\begin{array}{l}0.872 \\
(0.033)^{* * *}\end{array}$ & & & $\begin{array}{l}0.812 \\
(0.046)^{* * *}\end{array}$ \\
\hline Crosscosts & $\begin{array}{l}1.138 \\
(0.049)^{* * *}\end{array}$ & & & $\begin{array}{c}1.094 \\
(0.072)\end{array}$ \\
\hline Neighbour & $\begin{array}{l}0.320 \\
(0.075) * * *\end{array}$ & & & $\begin{array}{l}0.205 \\
(0.076)^{* * *}\end{array}$ \\
\hline Cluster 1 & $\begin{array}{l}10.919 \\
(4.470)^{* * *}\end{array}$ & & & $\begin{array}{l}15.052 \\
(7.863)^{* * *}\end{array}$ \\
\hline Cluster2 & $\begin{array}{l}2.641 \\
(0.816)^{* * *}\end{array}$ & & & $\begin{array}{c}1.883 \\
(0.770)\end{array}$ \\
\hline Cluster3 & $\begin{array}{l}2.157 \\
(0.711)^{* *}\end{array}$ & & & $\begin{array}{c}1.328 \\
(0.606)\end{array}$ \\
\hline Changed seat & $\begin{array}{l}3.290 \\
(1.084)^{* * *}\end{array}$ & & & $\begin{array}{c}5.060 \\
(5.371)\end{array}$ \\
\hline Spontaneity & & $\begin{array}{l}0.761 \\
(0.074)^{* * *}\end{array}$ & & $\begin{array}{c}0.998 \\
(0.128)\end{array}$ \\
\hline Social aspect & & $\begin{array}{c}1.061 \\
(0.071)\end{array}$ & & \\
\hline Locational aspect & & $\begin{array}{l}1.217 \\
(0.134)^{*}\end{array}$ & & $\begin{array}{c}1.030 \\
(0.124)\end{array}$ \\
\hline Self-assuredness & & & $\begin{array}{l}1.188 \\
(0.093)^{* *}\end{array}$ & $\begin{array}{l}1.261 \\
(0.103)^{* * * *}\end{array}$ \\
\hline Sociability & & & $\begin{array}{l}1.276 \\
(0.143)^{* *}\end{array}$ & $\begin{array}{l}1.286 \\
(0.161)^{* *}\end{array}$ \\
\hline Extroversion & & & $\begin{array}{l}0.738 \\
(0.090)^{* *}\end{array}$ & $\begin{array}{l}0.739 \\
(0.100)^{* *}\end{array}$ \\
\hline Pursuit of dominance & & & $\begin{array}{c}1.034 \\
(0.070)\end{array}$ & \\
\hline Masculinity & & & $\begin{array}{c}1.041 \\
(0.074)\end{array}$ & \\
\hline Observations & 125 & 80 & 80 & 80 \\
\hline Log likelihood & -446.03 & -271.80 & -271.27 & -242.86 \\
\hline
\end{tabular}

Notes:

Standard errors in parentheses.

$*$ significant at $10 \% ; * *$ significant at $5 \% ; * * *$ significant at $1 \%$. 
factors have an influence on the fact of whether a student sits in one of the original clusters or not.

The analysis reported in Table 4 reveals some interesting discrepancies. Neither psychological factors nor the self-declared seating preference explain why a person prefers to sit next to another student. Only locational aspect exerts a marginal influence. The self-declared preferences still do not exert an influence on the likelihood that someone places him- or herself in one of the emerging clusters. All psychological variables with the exception of masculinity, however, significantly affect the probability that a student joins a cluster. The risk that a subject chooses a cluster grows with the level of self-assurance, sociability and dominance; extroverted students have, however, a tendency to sit outside of these groups. This means that clusters are formed of students with a specific psychological background; segregation is thus also possible in the absence of a clearly visible standard of differentiation such as race. Students who are very self-confident and extroverted prefer not to sit in one of the clusters, whereas students who are very sociable more often choose such a seat. ${ }^{8}$

\section{Conclusion}

Following Schelling's (1969) ground-breaking article on segregation, we know that collective neighbourhood choices are not random. However, we often do not know what kind of factors guide these social decision-making processes. This article has shed some light on one situation that Schelling has used as an illustrative example for the development of his segregation model. In his view, seating behaviour in an auditorium is one of the processes in which independent individual decisions should lead to some predictable macro patterns.

Our classroom experiment has shown that segregation is possible even in situations in which the individual costs of a location decision are minimal and where no clear segregation criterion is visible. Seating behaviour is thus a social process that is guided by a mix of informal rules and individual predispositions. Obviously, the physical costs of going to a distant seat are an effective deterrent for people who arrive early. Other costs however, play, an important role, too. The social costs of sitting both too far away and too close to other participants are equally important factors. We contend that 


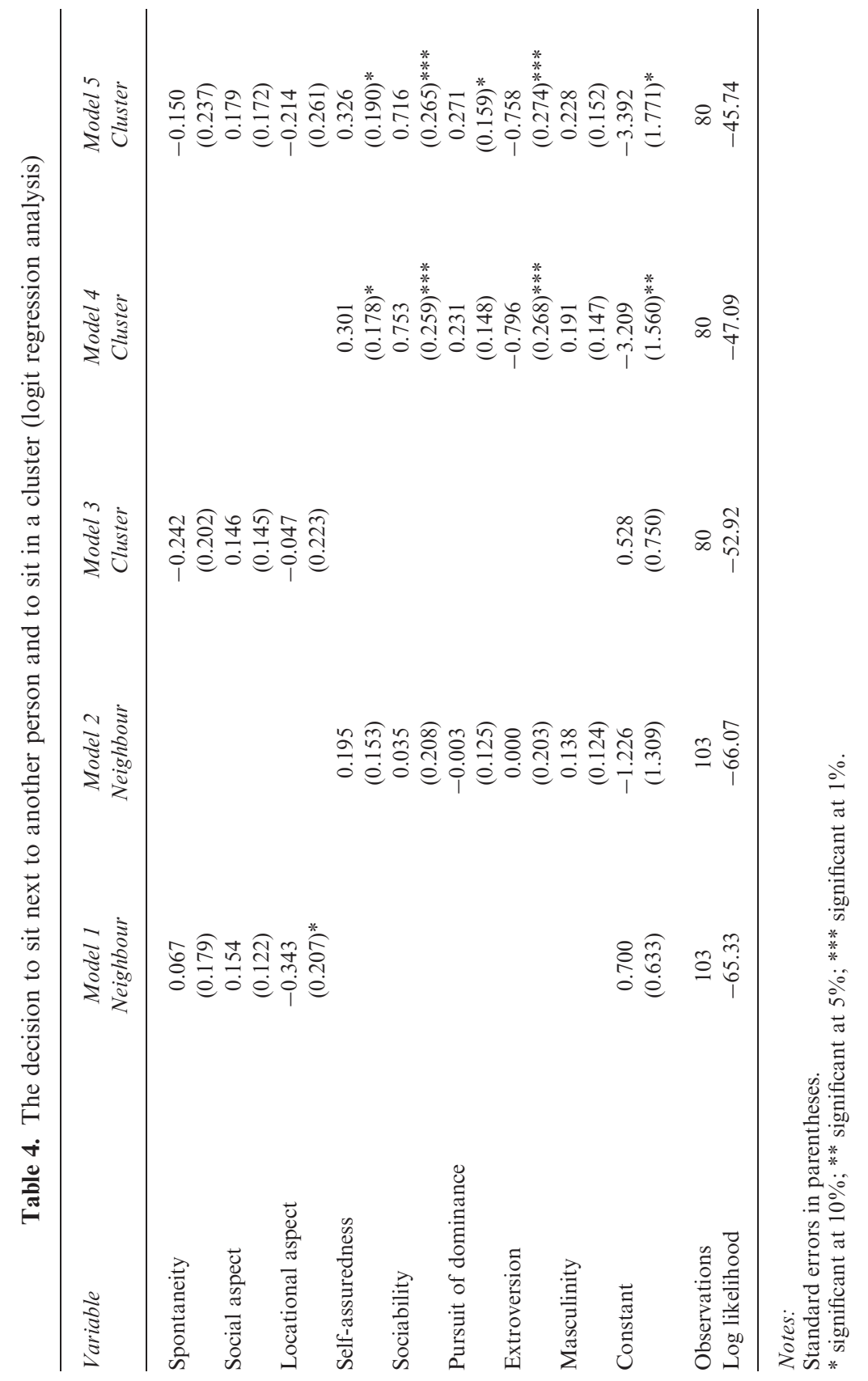


the clusters of early entrants serve as important signposts for latecomers. The social predisposition and the self-declared seating preferences are final sources of influence. The overall composition of the classroom shows that students with a certain profile tend to sit in groups.

Our findings generally support a large body of formal and computational studies that alert us to the danger of social polarization even in the absence of divisive preferences. Future studies should show how communication and institutions lessen or aggravate the conflictive tendencies that are inherent in group formation processes.

\section{Acknowledgements}

A previous version of this article was presented at the meeting of the working group on decision theory of the German Political Science Association, University of Bamberg, 9-10 July 2004. We received helpful comments from the participants as well as from two anonymous reviewers. This article is part of the PAC Project CIT-2-CT2004-506084. We would like to thank the European Commission for partial funding, Brigitte Rockstroh for her help with the psychological literature and Peter Hille, Lena Schaffer, Anna Ohm and Bettina Hafner for their assistance in setting up the experiment. The questionnaires and the replication dataset can be found on the following homepage: http://www.uni-konstanz.de/FuF/Verwiss/ GSchneider/downloads/daten.htm

\section{NOTES}

1. Pancas and Vriend (2003) prove that segregation is equilibrium behaviour even if individuals have a strict preference for perfect integration.

2. One example is the question of whether or not one normally prefers a seat in the back row or whether one prefers to sit next to a friend.

3. The Freiburger Persönlichkeitsinventar (FPI) was developed as an instrument specific to German probands; it is a standardized psychological tool, which works as well in clinical as in non-clinical diagnostics. It does not work well for probands with only low intelligence scores and for probands with little motivation. It is supposed to work very well in research situations. For these reasons we selected the FPI as an appropriate working tool for our research.

4. Two seats were part of both cluster 1 and cluster 2 and therefore received a positive value on both variables. 
5. The questions used to construct the particular indices can be found on the website of the second author (http://www/uni-konstanz.de/FuF/Verwiss/Gschneider/); we conducted principal component analysis to assure one-dimensional measurement.

6. Multicolinearity plays no role between these three variables, the highest correlation coefficient being 0.18 .

7. Each individual test score can be checked to see whether it deviates considerably from the expected value. The expected value is equal to the mean value of the calibration sample for the corresponding age group. In addition an expected distribution of the values was derived from this calibration sample to assess how many subjects should score a particular value. Of the subjects $20 \%$ are expected to reach the middle score $5,17 \% 4$ or $6,12 \% 3$ or $7,7 \% 2$ and 8 and $4 \% 1$ and 9 .

8. Interestingly the psychological variables also have an influence on whether a student is arriving too late for the lecture. For an extroverted and self-confident student the probability for arriving too late is significantly higher than for a sociable student.

\section{REFERENCES}

Batten, D.F. 2001. 'Complex Landscapes of Spatial Interaction.' Annals of Regional Science 35: 81-111.

Bobo, L. and C.L. Zubrinsky. 1996. 'Attitudes on Residential Integration: Perceived Status Differences, Mere In-group Preference, or Racial Prejudice?' Social Forces 74(3): 883-909.

Bruch, E.E. and R.D. Mare. 2003. 'Neighborhood Choice and Neighborhood Change.' Unpublished paper, University of California at Los Angeles.

Clark, W.A.V. 1991. 'Residential Preferences and Neighborhood Racial Segregation: A Test of the Schelling Segregation Model.' Demography 28(1): 1-19.

Clark, W.A.V. 1992. 'Residential Preferences and Residential Choices in a Multiethnic Context.' Demography 29(3): 451-66.

Clark, W.A.V. 2003. 'Ethnic Preferences and Ethnic Perceptions in Multi-Ethnic Settings.' Urban Geography 23(3): 237-56.

Emerson, M.O., K.J. Chai and G. Yancey. 2001. 'Does Race Matter in Residential Segregation? Exploring the Preferences of White Americans.' American Sociological Review 66(6): 922-35.

Farley R., C. Steeh, M. Krysan, T. Jackson and K. Reeves. 1994. 'Stereotypes and Segregation: Neighborhoods in the Detroit Area.' American Journal of Sociology 100(3): 750-80.

Krugman, P. 1994. 'Complex Landscapes in Economic Geography.' American Economic Review, Papers and Proceedings 84: 412-16.

Mann, L. and K.F. Taylor. 1969. 'Queue Counting: The Effect of Motives Upon Estimates of Numbers in Waiting Lines.' Journal of Personality and Social Psychology 12: $95-103$.

Pancs, R. and N.J. Vriend. 2003. 'Schelling's Spatial Proximity Model of Segregation Revisited.' Queen Mary University of London, Department of Economics Working Paper \# 487.

Pollicott, M. and H. Weiss. 2001. 'The Dynamics of Schelling-type Segregation Models and a Nonlinear Graph Laplacian Variational Problem.' Advances in Applied Mathematics 27: 17-40. 
Schelling, T.C. 1969. 'Models of Segregation.' American Economic Review, Papers and Proceedings 59(2): 488-93.

Schelling, T.C. 1971. 'Dynamic Models of Segregation.' Journal of Mathematical Sociology 1: 143-86.

Schelling, T.C. 1978. Micromotives and Macrobehavior. New York: W.W. Norton.

Schneider, G. and U.S. Krämer. 2004. 'The Limitations of Fair Division.' Journal of Conflict Resolution 48(4): 506-24.

Tirole, J. 2002. 'Rational Irrationality: Some Economics of Self-Management.' European Economic Review 46(4-5): 633-55.

GABRIELE RUOFF is a graduate student in public policy and management at the University of Konstanz, Germany and a fellow of the Deutsche Studienstiftung. She is the co-author of a survey article on quantitative methods in international relations research and is currently researching the kind of effects political events, in particular fiscal policy announcements, have on financial markets.

ADDRESS: Department of Politics and Management, Box D 86, University of Konstanz, 78457 Konstanz, Germany [email: gabiruoff@gmx.de]

GERALD SCHNEIDER has been professor of political science at the University of Konstanz, Germany, since 1997, where he holds the International Relations Chair. He is also executive editor of European Union Politics. His research interests lie in political decision making, European integration, the economic causes and consequences of armed conflict, and applied bargaining theory. He has published more than 90 scholarly articles and has recent and forthcoming publications in Acta Politica, European Journal of International Relations, European Political Science, European Journal of Political Research, Journal of Conflict Resolution, Millennium and Political Studies.

ADDRESS: Department of Politics and Management, Box D 86, University of Konstanz, 78457 Konstanz, Germany

[email: gerald.schneider@uni-konstanz.de] 